\title{
Targeting macrophage anti-tumor activity to suppress melanoma progression
}

\author{
Huafeng Wang ${ }^{1, *}$, Lijuan Zhang ${ }^{1,2, *}$, Luhong Yang ${ }^{1}$, Chengfang Liu ${ }^{3}$, Qi Zhang ${ }^{4}$ and \\ Linjing Zhang ${ }^{1}$ \\ ${ }^{1}$ Modern College of Arts and Science, or School of Life Science, Shanxi Normal University, Linfen, China \\ 2 Research Center of Basic Medical Sciences, Tianjin Medical University, Tianjin, China \\ ${ }^{3}$ Department of Human Anatomy, Shanxi Medical University, Shanxi Sheng, China \\ ${ }^{4}$ Nankai Hospital, Tianjin, China \\ * These authors have contributed equally to this work \\ Correspondence to: Huafeng Wang, email: wanghf@sxnu.edu.cn
}

Lijuan Zhang, email: lijuanzhang2010000@163.com

Linjing Zhang, email: linjingzh@aliyun.com

Keywords: melanoma; macrophage; GM-CSF; immunoadjuvant agent

Received: June 30, $2016 \quad$ Accepted: December 27, 2016 Published: January 03, 2017

\section{ABSTRACT}

By phagocytosing cancer cells and their cellular debris, macrophages play a critical role in nonspecific defense (innate immunity) and, as antigen presenters, they help initiate specific defense mechanisms (adaptive immunity). Malignant melanoma is a lethal disease due to its aggressive capacity for metastasis and resistance to therapy. For decades, considerable effort has gone into development of an effective immunotherapy for treatment of metastatic melanoma. In this review, we focus on the anti-tumor activities of macrophages in melanoma and their potential as therapeutic targets in melanoma. Although macrophages can be re-educated through intercellular signaling to promote tumor survival owing to their plasticity, we expect that targeting the anti-tumor activity of macrophages remains a promising strategy for melanoma inhibition. The combination of tumoricidal macrophage activation and other treatments such as surgery, chemotherapy, and radiotherapy, may provide an effective and comprehensive anti-melanoma strategy.

\section{INTRODUCTION}

Melanoma is one of the most dangerous cancers, illustrated by the fact that it represents less than $5 \%$ of all skin cancers but results in the majority of skin cancerrelated deaths [1]. In 2012, 232,000 people were diagnosed with melanoma globally and the disease resulted in 55,000 deaths [2]. It is estimated that in the United States there were 73,870 new cases and 9,940 deaths from melanoma in 2015 [3]. In mainland China, there are estimated to be about 20,000 new cases of melanoma annually [4], among which about $50-70 \%$ are primary skin melanoma skin and $6 \%$ are melanoma of the mucous membrane [5]. Malignant melanoma is lethal because of its aggressive capacity for metastasis and resistance to therapy [1]. Tumors can potentially be recognized as "altered self," akin to allogeneic immunity, leading to an anti-tumor immune response of potential value in the adjuvant setting. Therefore, researchers have begun to develop immunotherapy for treatment of metastatic melanoma [6]. This has motivated investigation of interactions between melanoma and immune cells and translation of this knowledge into effective clinical strategies.

Macrophages, first discovered by Elie Metchnikoff in 1884 [7], are a type of white blood cell, and also prodigious and industrious "janitors" in our body that engulf and digest junk or malignant cells, such as cancer cells or cellular debris in a process called phagocytosis [8]. Besides phagocytosis, they play a critical role in nonspecific defense (innate immunity) and, in their role as antigen presenters help initiate specific defense mechanisms (adaptive immunity) by recruiting other immune cells such as lymphocytes.

Macrophages, an important component of the innate immunity against tumors, are attracted by locally secreted chemokines [9]. Activated macrophages defend against 
tumors by direct tumor cytotoxicity and by secreting cytokines to recruit secondary immune cells, presenting antigen to $\mathrm{T}$ cells $[10,11]$, including melanoma $[12,13]$. However, owing to their plasticity, macrophages can be re-educated to alter their phenotype $[14,15]$. Substantial evidence indicates that macrophages in the context of the tumor microenvironment, rather than being tumoricidal, adopt a pro-tumor phenotype in vivo both in the primary and metastatic sites by the presence of growth factors in the tumor microenvironment as well as by intercellular interactions $[14,16]$. Consequently, there is a duality in the function of macrophages in tumor.

In this review, we focus on the anti-tumor role of macrophages in melanoma and its potential for therapeutic targeting.

\section{ADOPTIVE TRANSFER OF ACTIVATED IN VITRO MACROPHAGES}

Cytotoxic macrophages may occupy a major role in the defense mechanism to neoplasia [17]. While normal macrophages do not appear to be effective in attacking tumors, they can be induced to be cytotoxic in vitro by application of specific activators and then adoptive transfer can be performed on these induced macrophages to bring forth their anti-tumor effects in vivo.

\section{Xenogeneic macrophage activation strategies}

Macrophages can be induced to be cytotoxic in vitro using supernatants obtained from sensitized xenogeneic lymphocytes (Figure 1). The application of xenogeneic activated macrophages from tumor-bearing animals rendering them cytotoxic may provide a possible approach to therapy. As early as 1974, investigators studied the ability of syngeneic macrophages from C57BL/6 mice bearing a progressively growing B16 melanoma to inhibit established pulmonary metastases in vivo [12]. Peritoneal macrophages were isolated from C57BL/6 mice bearing progressively growing subcutaneous B16 melanoma that had been treated with thioglycollate. The macrophages were cultured in vitro with supernatants obtained from xenogeneic lymphocytes after their interaction with the tumor in vitro and were injected intravenously

\section{Tumor-bearing mice

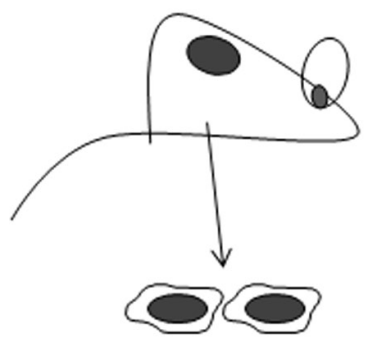 \\ Peritoneal macrophages
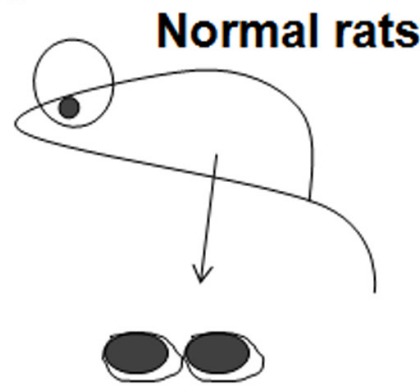 \\ Sensitized xenogeneic (rat) lymphocytes}

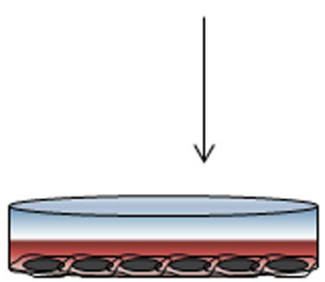

\section{Mice-derived macrophages were cultured in vitro with supernatants obtained from rat lymphocytes after their interaction with the tumor in vitro}

Specifically in vitro-treated macrophages injected i.v. into mice planted with melanoma cells

Figure 1: Xenogeneic activation of macrophages strategies. These macrophages were cultured in vitro with various supernatants obtained from xenogeneic lymphocytes after their interaction with the tumor in vitro 
(i.v.) into other C57BL/6 mice that had been given i.v. injections of 10,000 viable B16 melanoma cells $48 \mathrm{hr}$ previously. In vitro-treated macrophages injected i.v. into mice significantly reduced their number of established pulmonary metastases. Moreover, it appeared that the in vivo inhibition of tumor nodules was continuing at the time of sacrifice [12].

\section{Stimulating factor strategies}

Stimulated lymphocytes release a large number of biologically active mediators, some of which are chemotactic to macrophages, activating the macrophages and rendering them cytotoxic [17]. The potential anti-tumor activity of human macrophages, grown in macrophage colony stimulating factor (M-CSF), was examined in mice homozygous for the severe combined immune deficiency (SCID) mutation, bearing xenografts of autologous human melanoma [18]. Injection of the cultured macrophages, once or repeatedly, resulted in partial to complete regression of tumors [18].

\section{Microbe-associated factors}

Muramyl dipeptide (MDP) is the active immunomodulating component of mycobacterial cell walls contained in Freund's complete adjuvant [19]. Regardless of whether they are alveolar, peritoneal or hepatic, in vitro exposure of macrophages to MDP has been shown to render these cells tumoricidal in melanoma. F344 rat alveolar macrophages can be rendered tumoricidal against xenogeneic melanoma cells following incubation with both unencapsulated (free) MDP and liposomeencapsulated MDP [19]. Cultured liver macrophages can also be activated in vitro with both unencapsulated (free) MDP and liposome-encapsulated MDP to a tumoricidal state against melanoma [20]. Moreover, it was observed that encapsulation of MDP within liposomes substantially augments the MDP-induced cytotoxicity [20].

\section{ACTIVATING MACROPHAGES IN VIVO TO FIGHT AGAINST MELANOMA}

Cytotoxic macrophages against syngeneic tumor cells can also be induced in vivo, for example, by injecting immunomodulator-loaded liposomes intravenously [21].

\section{GM-CSF}

Among stimulating factors, GM-CSF is widely used to stimulate macrophages to become tumoricidal, and it requires no additional factors [22]. As a potential approach

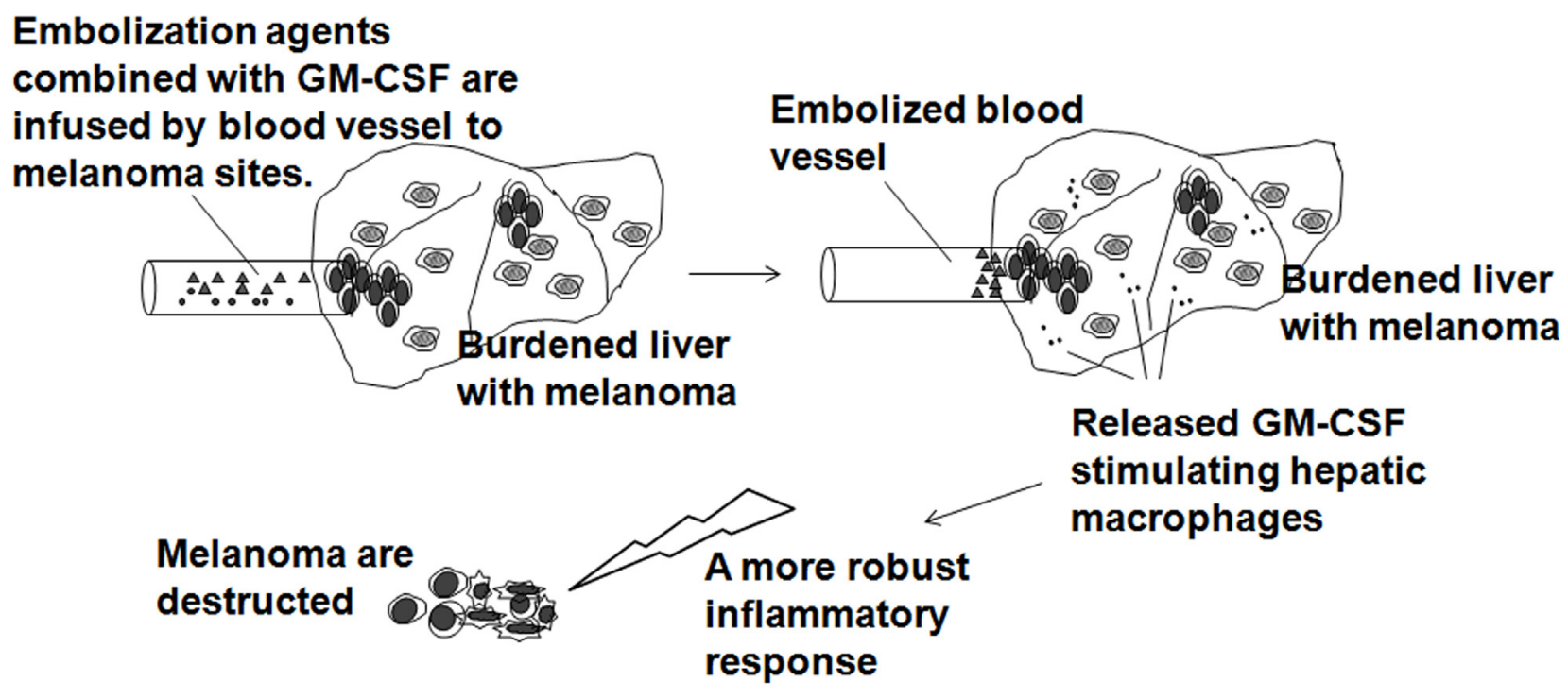

\section{Macrophages}

\section{Melanoma cell}

Figure 2: Immunoembolization with tumoricidal macrophage aggregation. Embolization agents combined with GM-CSF are infused by blood vessel to melanoma sites, which results in disruption of the tumor blood supply and the local immunologic reaction evoked by GM-CSF stimulating hepatic macrophages. 
to adjuvant immunotherapy, sequential intralesional administration of GM-CSF in dermal and subdermal melanoma lesions can induce immense antitumor immune response [23]. Evidence has been accumulated that GMCSF is useful as an immunoadjuvant agent for cancer vaccines [24]. Hogge and colleagues injected healthy dogs with lethally irradiated canine melanoma cells transfected with human GM-CSF and saw increased numbers of macrophages at the vaccination site [25]. In a further trial, Finocchiaro and Gilkin combined autologous/allogeneic formolized tumor cells as a vaccine injected concomitantly with lethally irradiated xenogeneic cells producing human GM-CSF to treat canine malignant melanoma patients [26]. In another surgery adjuvant approach, GM-CSF was combined with the periodic administration of lipoplexes carrying the gene of human GM-CSF at the time of surgery [27]. It was demonstrated that this surgery adjuvant combined treatment was significantly delayed or prevented postsurgical recurrence and distant metastasis, increasing disease-free and overall survival, and maintaining the quality of life [27].

\section{Immunoembolization}

GM-CSF, as an immunoadjuvant agent, has been used for the embolization of human melanoma. In 2008, a phase I trial that used human recombinant GM-CSF for immuno- embolization was reported [28]. There was no maximum-tolerated, dose-limiting dose or late toxicity found at doses as high as $2000 \mu \mathrm{g}$ of GMCSF, and higher doses correlated with longer systemic progression-free survival. A subsequent retrospective analysis that compared immuno- embolization with carmustine chemoembolization showed a significantly longer survival with immuno- embolization [29]. To further investigate the immunologic mechanism and efficacy of this approach, a randomized phase II clinical trial was designed. Immunoembolization with GM-CSF mixed with ethiodized oil was performed on patients with histologically confirmed metastatic uveal melanoma to the liver (contains more than $70 \%$ of all tissue macrophages) [30]. The investigators expected that local immunologic reaction evoked by GM-CSF would induce systemic immunity against melanoma cells and delay the development of remote systemic metastases [30]. The working hypothesis of the study was that immunoembolization would stimulate massive numbers of hepatic macrophages to induce a more robust inflammatory response, triggering a systemic immune recognition of uveal melanoma and delaying the progression of extrahepatic metastasis (Figure 2). These patients showed longer extrahepatic recurrence-free periods, presumably as a result of better immunologic control of circulating micrometastases [30]. The prognosis of patients with uveal melanoma with hepatic metastasis is extremely poor, and the overall survival is generally short: less than 1 year in most cases. Immunoembolization seems to be safe, easy to administer, and potentially effective. The results obtained in the study are encouraging; however, further clinical and basic research is needed to optimize and improve the efficacy of immuno- embolization.

\section{Galectin-9}

Galectin-9, a $\beta$-galactoside-binding lectin, is closely associated with reduced metastasis and low recurrence in patients with malignant melanoma [31]. Intravenous galectin-9 administration reduced lung metastasis of B16F10 in an experimental mouse model [32]. It was reported that galectin-9 treatment could expand the population of unique macrophages with a plasmacytoid cell-like phenotype, and therefore promotes NK cellmediated anti-tumor activity and significantly prolongs the survival of B16F10 melanoma-bearing mice [33].

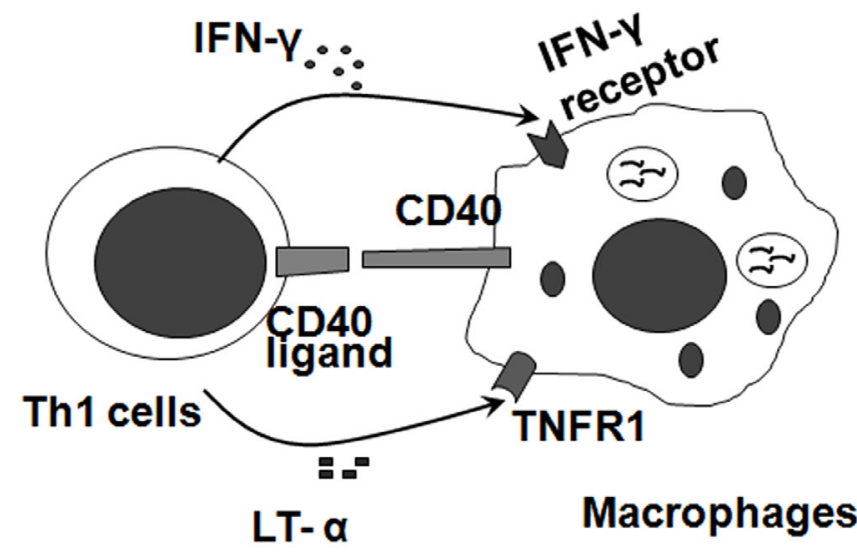

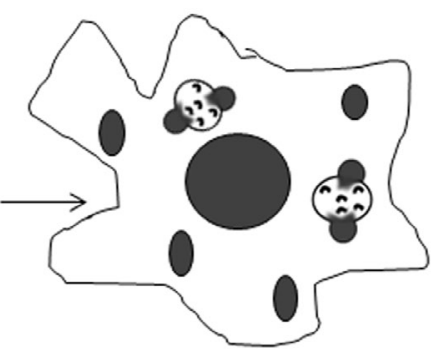

$\because \because=$

Tumoricidal species such as ROS, NO and so on.

\section{Tumor-killing Macrophages}

Figure 3: Tumoricidal macrophages are induced by Th1 cells. Th1 cells characteristically express IFN- $\gamma$, CD40 ligand, lymphotoxin-alpha (LT- $\alpha$ ) by their receptors on macrophages to stimulate macrophages into the potent tumoricidal effector cells, which generate tumoricidal reactive oxygen and nitrogen species, and enhance fusion of phagosomes with lysosomes. 


\section{Homeopathy}

In Europe homeopathy is very popular as a complementary and alternative medical therapy [34]. Many cancer patients treated with homeopathic approaches show an increase in their ability to fight cancer, improvement of their physical and emotional well-being, and alleviation of their pain resulting from the disease or conventional treatments [34]. Here, we describe the results of an experimental laboratory validation of the potential of peritoneal macrophages, challenged with a complex homeopathic medication, to stimulate the immune effectiveness of mesenteric lymph node lymphocytes. This new form of immunomodulatory therapy is based on Hahnemann's ancient homeopathic techniques, which use diluted substances that are vigorously shaken during preparation. Macrophages activated with a complex Brazilian homeopathic medication showed an improvement in the anti-cancer immune response against a very aggressive lineage of melanoma cells when cocultured with lymphocytes [35].

\section{Microbe strategies}

Vaccination with intracellular pathogens such as Bacille Calmette-Guerin (BCG), vaccinia virus, and Chlamydophila pneumoniae significantly decreased the incidence of melanoma [36] and increased survival in metastatic melanoma [37]. It was observed that microbes induce the cytotoxicity of macrophages toward melanoma, which is illustrated by the increased complex antitumor response such as expression of CCL2, CCL3, IL-6, CXCL10, CCL7, CD80, CXCL11, CXCL9 and IL-23 by macrophages [37].

\section{Nanoparticles}

It was reported that polyhydroxylated fullerenols $\left(\mathrm{Gd} @ \mathrm{C}_{82}(\mathrm{OH})_{22}\right.$ nanoparticles) could induce murine melanoma cell death in vitro, and inhibit tumor formation and metastasis in vivo, by directly promoting macrophage viability, phagocytosis, and the secretion of cytokines by macrophages [38].

\section{Th1 cells}

Th1 cells have an important role in the tumoricidal activity of macrophages. Th1 cells produce cytokines to stimulate macrophages into the potent tumoricidal effector cells (Figure 3). In a Phase I clinical trial investigating the biologic activity of vaccination with irradiated autologous melanoma cells engineered to secrete human GM-CSF in patients with metastatic melanoma, it was demonstrated that immunization sites were intensely infiltrated with $\mathrm{T}$ lymphocytes and macrophages in all 21 evaluated patients and resulted in extensive tumor destruction [39]. In early reports, it was shown that Th1 cytokine mRNA for CD38, lymphotoxin (TNF- $\beta$ ), and IL-2 were significantly elevated in the ten regressing melanomas compared to the ten non-regressing melanomas [40]. IFN- $\gamma$ mRNA was also elevated in regressing melanomas but failed to reach statistical significance [40]. This study shows an association between Th1 cytokines and spontaneously regressing melanomas. High expression of Th1-biasing cytokines IL-12 and IFN- $\alpha$ leads to a Th1-like phenotype and suppressed melanoma growth [41]. Another important function of Th1 cells is the recruitment of macrophages. Th1 cells produce the hematopoietic growth factors IL-3 and GM-CSF, which stimulate the production of new phagocytic cells in the bone marrow.

Vice versa, activated macrophages secrete IL-12, which increases the amount of IFN- $\gamma$ produced by Th1 cells and also promotes the differentiation of activated naive CD4 T cells into Th1 effector cells. Interleukin-12transfected B16 melanoma showed retarded tumor growth in syngeneic mice [42]. In a recent study, neoadjuvant local low-dose gamma irradiation can program the differentiation of iNOS M1 macrophages to exert antitumor effects on a xenotransplant mouse melanoma model through iNOS by inducing endothelial activation and the expression of Th1 chemokines and by suppressing the production of angiogenic, immunosuppressive, and tumor growth factors [43].

\section{BIPHASIC FACTORS}

\section{IFN- $\gamma$}

IFN- $\gamma$ is the effector cytokine of Th1 helper cells and after Th1 activation macrophages, as the main effector cells of Th1 immunity, are activated to kill microorganisms and tumor cells and produce copious amounts of proinflammatory cytokines (Figure 3). Therefore, administration of IFN- $\gamma$ suppresses melanoma development by activating macrophages (Figure 4 left). IFN- $\gamma$, which can be produced by macrophages, has a direct antitumor effect on melanoma cells [44-47]. IFN- $\gamma$ plays a role in the response to melanoma indirectly through its effect on the immune system and directly through its anti-proliferative and pro-apoptotic effects on melanoma cells [44]. IFN- $\gamma$ added to A375 melanoma cells caused an additive growth inhibitory response [45]. The combination of IFN- $\gamma$ with IFN- $\alpha$ or IFN- $\beta$ resulted in a strong synergistic anti-proliferative activity on four human melanoma cell lines (StML-11, StML-12, StML14, and SKMel-28) [46]. The changes in gene expression associated with the direct anti-melanoma effect of IFN- $\gamma$ were striking, as these involved genes or groups of genes 
previously implicated in the malignant phenotype of melanoma as well as genes not previously thought to be involved in melanoma growth and survival [47].

Several reports have suggested that IFN- $\gamma$ may also have pro-tumorigenic effects in solid tumors under certain circumstances $[46,48]$. Although IFN- $\gamma$ reduces cellular growth in vitro, when introduced in vivo along with intravenously inoculated B16 melanoma cells, it induces lung colonization and enhanced expression of class I major histocompatibility complex antigens (Figure 4 right) $[46,48]$, which are more frequently expressed in advanced melanoma and related to an increased risk of metastasis in primary melanoma [46]. Elevated levels of IFN- $\gamma$ may be an independent predictor of disease recurrence and may be used to identify a group of early-stage melanoma patients who are more likely to have recurrence of disease and who may benefit from adjuvant therapies, including immunotherapies [49]. In fact, a Southwest Oncology Group-randomized clinical trial showed that IFN- $\gamma$ had an adverse effect on melanoma relapse and mortality rates [50]. In an ultraviolet B-irradiated mouse skin cancer model, macrophage-produced IFN- $\gamma$ promotes melanoma growth by inhibiting apoptosis [51]. Pro-tumorigenic effects of IFN- $\gamma$ may be, in part, due to pro-expression of CD74 in melanoma [52] (Figure 4 right).

\section{Monocyte chemoattractant protein-1 (MCP-1)}

MCP-1 is a potent macrophage-recruiting molecule [53]. It was reported that MCP-1 was expressed during the early stages of human malignant melanoma, and it recruits macrophages and promotes tumor angiogenesis and growth [54]. However, MCP-1 action is biphasic in that high levels promote massive monocyte/ macrophage accumulation and tumor destruction, whereas low or intermediate levels support tumor growth [55].

\section{IL-1及}

IL-1 $\beta$ is a pleiotropic pro-inflammatory cytokine involved in cell growth, differentiation, and regulation of immune responses [56]. It has been reported that the expression levels of the IL- $1 \beta$ gene or protein are associated with the invasiveness and metastasis of melanoma [57]. Metastatic melanoma cell lines do not secrete IL-1 $\beta$ but promote IL- $1 \beta$ production from macrophages [58]. A better understanding of the mechanisms and consequences of IL- $1 \beta$ production by infiltrating macrophages may be of interest for the development of IL-1 $\beta$ targeted therapy, such as anti-IL-1 $\beta$

\section{Administration of IFN-Y}

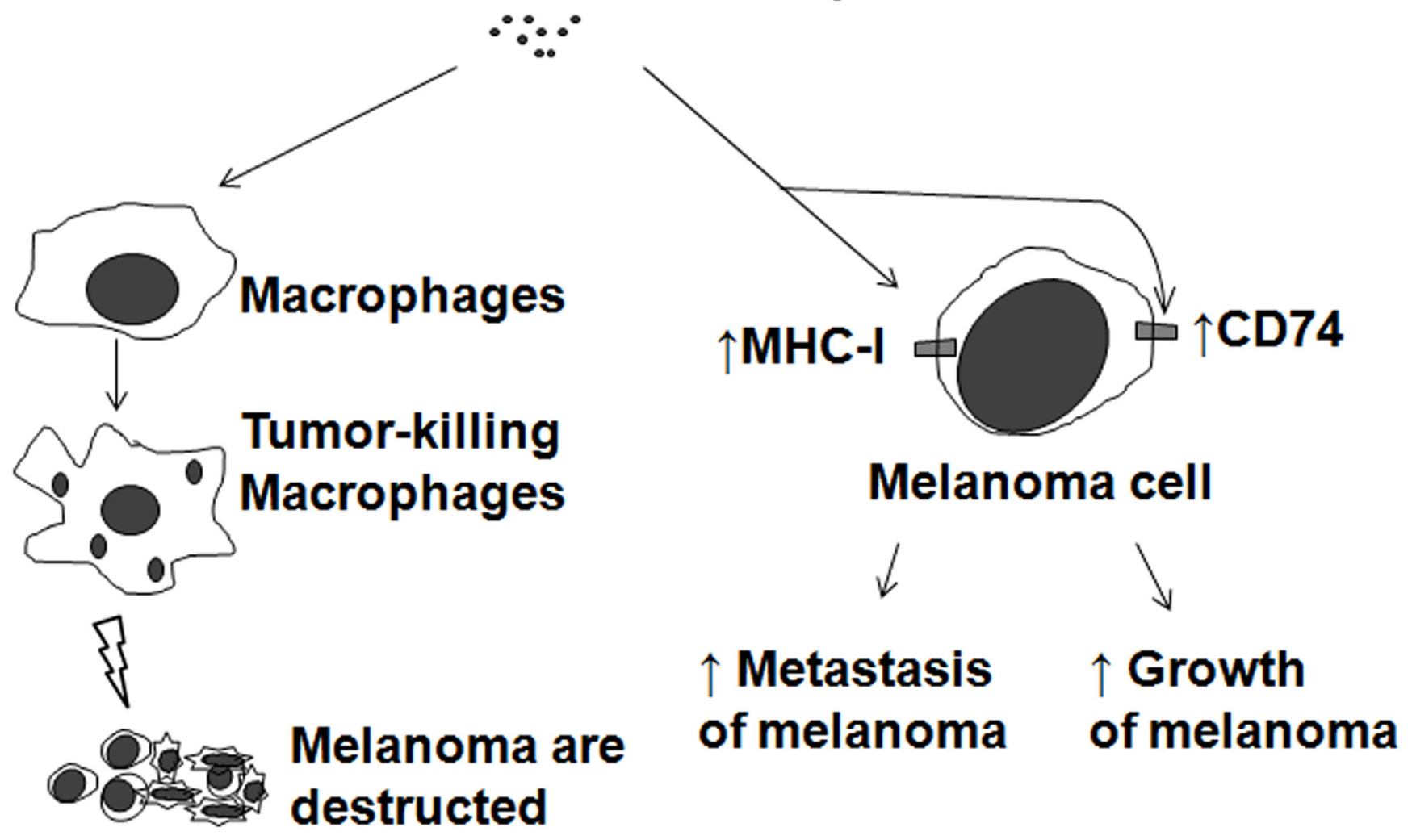

Figure 4: Biphasic effects of IFN- $\gamma$ on melanoma. Application of IFN- $\gamma$ to melanoma treatment (Left). Adverse effects of IFN- $\gamma$ on melanoma by pro-expression of MHC-I or CD74 (Right). 
antibody (canakinumab), against metastatic melanoma. On the other hand, IL-1 $\beta$ production from tumor cells may be considered a threat by the host's immune system. In this aspect, it has been reported that IL-1 $\beta$-producing melanoma cells induce reduced tumor growth by recruiting immune cells [59].

\section{BLOCKAGE INHIBITION OF MELANOMA MIGRATION \\ TO MACROPHAGE}

Melanoma inhibits macrophage activation by suppressing TLR-4 signaling [60]. Tumors may also express co-inhibitory or immune checkpoint proteins that shield them from attack by immune effector cells, such as macrophages [61]. For example, melanoma cells release programmed cell death-1 ligand [62], activation of its cognate receptor in macrophages [63], leads to apoptosis of the latter (Figure 5). It was observed that melanoma cell lines and metastatic melanomas expressed larger amounts of macrophage inhibitory cytokine-1 (MIC-1) than melanocytes, nevi, and primary lesions of melanoma [64-69]. Melanoma cells produce MIC-1 to protect against NK cell-mediated killing by inhibition of macrophage migration [69] (Figure 5). Knockdown of MIC-1 expression in melanomas resulted in a significant decrease in tumorigenicity $[64,70]$ by retarding vascular development [71]. CD74, also known as major histocompatibility complex class II-associated invariant chain, has been identified as the high-affinity receptor for the cytokine MIC-1 [72, 73]. It was reported that CD74 is expressed in melanoma but not in benign melanocytes using a melanoma progression tissue microarray [66]. In a xenograft melanoma model established by cell surface CD74-negative MeWo cells subcutaneously injected into the flank of SCID Beige mice, MIC-CD74 inhibition by MIC inhibitor ISO-1 suppresses tumor growth significantly [52].

\section{CHALLENGE OF PRO-TUMOR M2-TYPE MACROPHAGES}

It should be noted that, owing to their plasticity, macrophages can be re-educated to adopt anti- inflammatory or pro-tumor M2-type, which often happens during late stage of inflammatory reaction. Studies using the B16 melanoma model have documented a gradual shift of initial Th0-, mixed Th1-/Th2-type CD4T cell response to Th2/Treg-type dominated responses by 14-20 days of progressive tumor growth [42, 74-76]. CD4Th2 cells and various regulatory cells produce cytokines such as TGF- $\beta 1$ and IL-10 that can educate the macrophages to become protumor M2-type. Injection of neutralizing anti-IL-4, -IL-10, or -TGF- $\beta 1$ antibodies can prevent this tumorinduced functional transition, resulting in enhanced CD8+ CTL generation and protection against tumor growth [74]. Depletion of CD4 T cells with locally secreted IL-12 in late-stage progressive B16 models, where Th2/Tr-type response dominate, eliminates Th2 cells and results in a Th1-dominant cytokine profile in tumor draining lymph nodes and leads to a retarded tumor growth in syngeneic mice [42].

Another solution to avoid a worst case scenario in the therapeutic strategy of macrophage activation is to use a high dose of macrophage recruitment factors, which can cause a massive accumulation of macrophages in a very short time. This artificial reaction is similar to the earlier stage of inflammatory reaction and the recruited macrophages are prone to fight the tumor, which is illustrated by application of MCP-1 [55] and GM-CSF [28].

\section{DISCUSSION}

Macrophages serve as a first-line of defense against pathogens and environmental insults through release of anti-microbe mediators such as pro-inflammatory cytokines [77]. Cancer cells and their cellular debris do not present the types of proteins specific to the surface of healthy somatic cells, which stimulates macrophages to devour the cancer cells. Therefore, macrophages are important components of the innate immunity against tumors [9]. However, the complexity of tissue environments may render macrophages, which already possess functional diversification and plasticity, able to acquire pro- and anti-inflammatory properties, which then can be classified into two types, as pro-inflammatory or anti-tumor M1-type and anti-inflammatory or pro-tumor M2-type macrophages [78]. Moreover, a large body

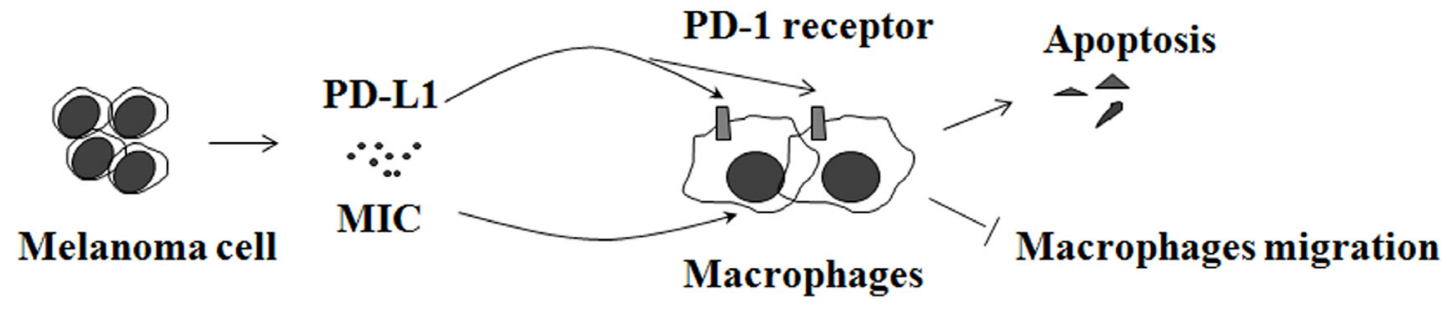

Figure 5: Melanoma inhibits macrophages. Melanoma cell release programmed cell death-1 ligand 1 (PD-L1) and macrophage inhibitory cytokine-1 (MIC) that suppress the macrophage activation. 
of evidence points to the tumorigenic populations of macrophages, and the macrophage-mediated anti-tumor therapy is faced with being abandoned.

Recently, we found that macrophages from D7Ertd443e knockout mice exhibit tumoricidal activities and adoptive transfer of both bone marrow-derived and peritoneal macrophages, after stimulation with M-CSF in vitro, results in inhibition of melanoma growth in vivo (data not published). Genetically modified cellbased vaccines encoding cytokines and co-stimulatory molecules allow sustained local release of cytokines to enhance a potent local inflammatory response without generating systemic side effects. GM-CSF appears to be the strongest promoter of local macrophages that can cause a macrophage-mediated anti-tumor inflammatory response at the vaccination site. It is expected that targeting the antitumor activity of macrophages is a promising approach for melanoma inhibition. We also suggest that the combination of tumoricidal macrophage activation and other treatments such as surgery, chemotherapy and radiotherapy, could be an effective and comprehensive anti-melanoma strategy.

\section{ACKNOWLEDGMENTS}

This work was supported by One College One Policy Project, Modern College of Arts and Science, Shanxi Normal University (2016KJYJ-6); Scientific Research Foundation for Doctor, Shanxi Normal University (0505/02070293) ); The Natural Science Foundation of Shanxi Province (2015021177); Shanxi Provincial University Science and Technology Innovation Project (20161107); National Natural Science Foundation of China (41571499); Natural Science Foundation of China (81602496).

\section{CONFLICTS OF INTEREST} interest.

The authors declare that there is no conflict of

\section{Author contributions}

H.W. and L.Z. conceived the article. H.W., L.Z., L.Y., C.L. and Q.Z. performed the draft. H.W. and L.Z. contributed to the final manuscript. All authors reviewed the manuscript.

\section{REFERENCES}

1. (August 25, 2015 ). Melanoma Treatment-for health professionals (PDQ ${ }^{\circledR}$ ) National Cancer Institute (USA)).

2. Organization WH. (2014). World cancer report, 2014. WHO Report Geneva: WHO, pp. Chapter 5.14.

3. Siegel RL, Miller KD and Jemal A. Cancer statistics, 2015. CA Cancer J Clin. 2015; 65(1):5-29.
4. committee; Cme. China's guidelines of diagnosis and treatment of melanoma(2011). Chinese Clinical Oncology. 2012; (02):159-171.

5. Han $\mathrm{Y}$ and $\mathrm{Qu} X$. The current situations and advances in cutaneous malignant melanoma. Modern Journal of Integrated Traditional Chinese and Western Medicine. 2015; (30):3416-3420.

6. Wieder $\mathrm{T}$, Brenner E, Braumuller $\mathrm{H}$ and Rocken $\mathrm{M}$. Immunotherapy of melanoma: efficacy and mode of action. J Dtsch Dermatol Ges. 2016; 14(1):28-36.

7. Kaufmann SH. Elie Metchnikoff's and Paul Ehrlich's impact on infection biology. Microbes and Infection. 2008; 10(14):1417-1419.

8. Mosser DM and Edwards JP. Exploring the full spectrum of macrophage activation. Nature reviews Immunology. 2008; 8(12):958-969.

9. Brigati C, Noonan DM, Albini A and Benelli R. Tumors and inflammatory infiltrates: friends or foes? Clinical \& experimental metastasis. 2002; 19(3):247-258.

10. Chattopadhyay $U$ and Bhattacharyya $S$. Effect of Monosaccharides on Tumor Associated Macrophage Mediated Phagocytosis of Autologous Tumor-cells. Medical Science Research Biochemistry. 1987; 15(56):325-326.

11. Gifford GE, Loewenstein J, Yamin A and Gallily R. Correlation of macrophage-mediated tumor-cell lysis with the production of macrophage cytolytic factor (CF). preliminary characterization of a factor inhibiting $\mathrm{cf}$ production. International journal of cancer. 1986; 37(1):7379.

12. Fidler IJ. Inhibition of pulmonary metastasis by intravenous injection of specifically activated macrophages. Cancer research. 1974; 34(5):1074-1078.

13. Kozłowska $\mathrm{K}$ and Cichorek M. Heterogeneity of peritoneal macrophages in hamsters-bearing transplantable melanomas in relation to their transglutaminase. Folia histochemica et cytobiologica/Polish Academy of Sciences, Polish Histochemical and Cytochemical Society. 1990; 29(4):141147.

14. Mills CD, Kincaid K, Alt JM, Heilman MJ and Hill AM. M-1/M-2 macrophages and the Th1/Th2 paradigm. The Journal of Immunology. 2000; 164(12):6166-6173.

15. Murray PJ, Allen JE, Biswas SK, Fisher EA, Gilroy DW, Goerdt S, Gordon S, Hamilton JA, Ivashkiv LB and Lawrence T. Macrophage activation and polarization: nomenclature and experimental guidelines. Immunity. 2014; 41(1):14-20.

16. Biswas SK, Allavena P and Mantovani A. (2013). Tumor-associated macrophages: functional diversity, clinical significance, and open questions. Seminars in immunopathology: Springer), pp. 585-600.

17. McKee WD. Immunological defenses in cancer. The Western journal of medicine. 1974; 121(1):55-56.

18. Chakraborty N, Okino T, Stabach P, Padula S, Yamase H, Morse E, Sha'afi R, Twardzik D, Shultz L and Mukherji 
B. Adoptive transfer of activated human autologous macrophages results in regression of transplanted human melanoma cells in SCID mice. In vivo (Athens, Greece). 1990; 5(6):609-614.

19. Sone $\mathrm{S}$ and Fidler IJ. In vitro activation of tumoricidal properties in rat alveolar macrophages by synthetic muramyl dipeptide encapsulated in liposomes. Cellular Immunology. 1981; 57(1):42-50.

20. Daemen T, Veninga A, Roerdink FH and Scherphof GL. In vitro activation of rat liver macrophages to tumoricidal activity by free or liposome-encapsulated muramyl dipeptide. Cancer research. 1986; 46(9):4330-4335.

21. Barratt G, Nolibe D, Yapo A, Petit J-F and Tenu J-P. (1987). Use of mannosylated liposomes for in vivo targeting of a macrophage activator and control of artificial pulmonary metastases. Annales de 1'Institut Pasteur/Immunologie: Elsevier), pp. 437-450.

22. Grabstein KH, Urdal DL, Tushinski RJ, Mochizuki DY, Price VL, Cantrell MA, Gillis S and Conlon PJ. Induction of macrophage tumoricidal activity by granulocytemacrophage colony-stimulating factor. Science. 1986; 232(4749):506-508.

23. Elias E and Sharma B. Sequential Intralesional Administration of Granulocyte-Macrophage Colony Stimulating Factor (GM-CSF) and Interleukin-2 (IL-2) in Dermal and Subdermal Melanoma Lesions Can Induce Immense Antitumor Immune Response: A Potential New Approach to Adjuvant Immunotherapy. Journal of Surgical Research. 2014; 2(186):682.

24. Dranoff G. GM-CSF-based cancer vaccines. Immunol Rev. 2002; 188:147-154.

25. Hogge GS, Burkholder JK, Culp J, Albertini MR, Dubielzig RR, Yang NS and MacEwen EG. Preclinical development of human granulocyte-macrophage colony-stimulating factor-transfected melanoma cell vaccine using established canine cell lines and normal dogs. Cancer gene therapy. 1999; 6(1):26-36.

26. Finocchiaro LM and Glikin GC. Cytokine-enhanced vaccine and suicide gene therapy as surgery adjuvant treatments for spontaneous canine melanoma. Gene therapy. 2008; 15(4):267-276.

27. Finocchiaro LM, Fondello C, Gil-Cardeza ML, Rossi UA, Villaverde MS, Riveros MD and Glikin GC. CytokineEnhanced Vaccine and Interferon-beta plus Suicide Gene Therapy as Surgery Adjuvant Treatments for Spontaneous Canine Melanoma. Human gene therapy. 2015; 26(6):367376.

28. Sato T, Eschelman DJ, Gonsalves CF, Terai M, Chervoneva I, McCue PA, Shields JA, Shields CL, Yamamoto A, Berd $\mathrm{D}$, Mastrangelo MJ and Sullivan KL. Immunoembolization of malignant liver tumors, including uveal melanoma, using granulocyte-macrophage colony-stimulating factor. Journal of clinical oncology. 2008; 26(33):5436-5442.

29. Yamamoto A, Chervoneva I, Sullivan KL, Eschelman DJ,
Gonsalves CF, Mastrangelo MJ, Berd D, Shields JA, Shields CL, Terai M and Sato T. High-dose immunoembolization: survival benefit in patients with hepatic metastases from uveal melanoma. Radiology. 2009; 252(1):290-298.

30. Valsecchi ME, Terai M, Eschelman DJ, Gonsalves CF, Chervoneva I, Shields JA, Shields CL, Yamamoto A, Sullivan KL, Laudadio M, Berd D, Mastrangelo MJ and Sato T. Double-blinded, randomized phase II study using embolization with or without granulocyte-macrophage colony-stimulating factor in uveal melanoma with hepatic metastases. Journal of vascular and interventional radiology. 2015; 26(4):523-532.e522.

31. Kageshita T, Kashio Y, Yamauchi A, Seki M, Abedin MJ, Nishi N, Shoji H, Nakamura T, Ono T and Hirashima M. Possible role of galectin-9 in cell aggregation and apoptosis of human melanoma cell lines and its clinical significance. International journal of cancer. 2002; 99(6):809-816.

32. Nobumoto A, Nagahara K, Oomizu S, Katoh S, Nishi N, Takeshita K, Niki T, Tominaga A, Yamauchi A and Hirashima M. Galectin-9 suppresses tumor metastasis by blocking adhesion to endothelium and extracellular matrices. Glycobiology. 2008; 18(9):735-744.

33. Nobumoto A, Oomizu S, Arikawa T, Katoh S, Nagahara K, Miyake M, Nishi N, Takeshita K, Niki T and Yamauchi A. Galectin-9 expands unique macrophages exhibiting plasmacytoid dendritic cell-like phenotypes that activate NK cells in tumor-bearing mice. Clinical immunology. 2009; 130(3):322-330.

34. Milazzo S, Russell N and Ernst E. Efficacy of homeopathic therapy in cancer treatment. European Journal of Cancer. 2006; 42(3):282-289.

35. Guimarães FS, Abud AP, Oliveira SM, Oliveira CC, César B, Andrade LF, Donatti L, Gabardo J, Trindade ES and Buchi DF. Stimulation of lymphocyte anti-melanoma activity by co-cultured macrophages activated by complex homeopathic medication. BMC cancer. 2009; 9(1):1.

36. Krone B, Kolmel KF, Henz BM and Grange JM. Protection against melanoma by vaccination with Bacille CalmetteGuerin (BCG) and/or vaccinia: an epidemiology-based hypothesis on the nature of a melanoma risk factor and its immunological control. European journal of cancer (Oxford, England : 1990). 2005; 41(1):104-117.

37. Buzas K, Marton A, Vizler C, Gyukity-Sebestyen E, Harmati M, Nagy K, Zvara A, Katona RL, Tubak V, Endresz V, Nemeth IB, Olah J, Vigh L, Biro T and Kemeny L. Bacterial Sepsis Increases Survival in Metastatic Melanoma: Chlamydophila Pneumoniae Induces Macrophage Polarization and Tumor Regression. The Journal of investigative dermatology. 2016; 136(4):862865.

38. Tang J, Chen Z, Sun B, Dong J, Liu J, Zhou H, Wang L, Bai R, Miao Q and Zhao Y. Polyhydroxylated fullerenols regulate macrophage for cancer adoptive immunotherapy and greatly inhibit the tumor metastasis. Nanomedicine. 2015. 
39. Soiffer R, Lynch T, Mihm M, Jung K, Rhuda C, Schmollinger JC, Hodi FS, Liebster L, Lam P and Mentzer $\mathrm{S}$. Vaccination with irradiated autologous melanoma cells engineered to secrete human granulocyte-acrophage colonystimulating factor generates potent antitumor immunity in patients with metastatic melanoma. Proceedings of the National Academy of Sciences of the United States of America. 1998; 95(22):13141-13146.

40. Lowes MA, Alex Bishop G, Crotty K, Barnetson RSC and Halliday GM. T Helper 1 Cytokine mRNA Is Increased in Spontaneously Regressing Primary Melanomas. Journal of Investigative Dermatology. 1997; 108(6):914-919.

41. Tüting T, Wilson CC, Martin DM, Kasamon YL, Rowles J, Ma DI, Jr SC, Wagner SN, Van dBP and Baar J. Autologous human monocyte-derived dendritic cells genetically modified to express melanoma antigens elicit primary cytotoxic $\mathrm{T}$ cell responses in vitro: enhancement by cotransfection of genes encoding the Th1-biasing cytokines IL-12 and IFN-alpha. Journal of Immunology. 1998; 160(3):1139-1147.

42. Nishida $\mathrm{T}$, Harashima N, Kitahara $\mathrm{N}$ and Shibata S. Elimination of CD4(+) T cells enhances anti-tumor effect of locally secreted interleukin-12 on B16 mouse melanoma and induces vitiligo-like coat color alteration. Journal of Investigative Dermatology. 2000; 115(6):1059-1064.

43. Klug F, Prakash H, Huber Peter E, Seibel T, Bender N, Halama N, Pfirschke C, Voss Ralf H, Timke C, Umansky L, Klapproth K, Schäkel K, Garbi N, Jäger D, Weitz J, Schmitz-Winnenthal H, et al. Low-Dose Irradiation Programs Macrophage Differentiation to an iNOS+/M1 Phenotype that Orchestrates Effective T Cell Immunotherapy. Cancer Cell. 2013; 24(5):589-602.

44. Dummer W, Niethammer AG, Baccala R, Lawson BR, Wagner N, Reisfeld RA and Theofilopoulos AN. T cell homeostatic proliferation elicits effective antitumor autoimmunity. The Journal of clinical investigation. 2002; 110(2):185-192.

45. Brown TJ, Lioubin MN and Marquardt H. Purification and characterization of cytostatic lymphokines produced by activated human $\mathrm{T}$ lymphocytes. Synergistic antiproliferative activity of transforming growth factor beta 1 , interferon-gamma, and oncostatin $\mathrm{M}$ for human melanoma cells. Journal of immunology (Baltimore, Md : 1950). 1987; 139(9):2977-2983.

46. Garbe C, Krasagakis K, Zouboulis CC, Schröder K, Krüger $\mathrm{S}$, Stadler $\mathrm{R}$ and Orfanos CE. Antitumor activities of interferon alpha, beta, and gamma and their combinations on human melanoma cells in vitro: changes of proliferation, melanin synthesis, and immunophenotype. Journal of Investigative Dermatology. 1990; 95.

47. Gollob JA, Sciambi CJ, Huang Z and Dressman HK. Gene expression changes and signaling events associated with the direct antimelanoma effect of IFN-gamma. Cancer research. 2005; 65(19):8869-8877.

48. Taniguchi K, Petersson M, Höglund P, Kiessling R,
Klein $\mathrm{G}$ and Kärre K. Interferon gamma induces lung colonization by intravenously inoculated B16 melanoma cells in parallel with enhanced expression of class I major histocompatibility complex antigens. Proceedings of the National Academy of Sciences. 1987; 84(10):3405-3409.

49. Porter GA, Abdalla J, Lu M, Smith S, Montgomery D, Grimm E, Ross MI, Mansfield PF, Gershenwald JE and Lee JE. Significance of plasma cytokine levels in melanoma patients with histologically negative sentinel lymph nodes. Annals of surgical oncology. 2001; 8(2):116-122.

50. Meyskens FL, Kopecky KJ, Taylor CW, Noyes RD, Tuthill RJ, Hersh EM, Feun LG, Doroshow JH, Flaherty LE and Sondak VK. Randomized trial of adjuvant human interferon gamma versus observation in high-risk cutaneous melanoma: a Southwest Oncology Group study. Journal of the National Cancer Institute. 1995; 87(22):1710-1713.

51. Zaidi MR, Davis S, Noonan FP, Graff-Cherry C, Hawley TS, Walker RL, Feigenbaum L, Fuchs E, Lyakh L and Young HA. Interferon- [ggr] links ultraviolet radiation to melanomagenesis in mice. Nature. 2011; 469(7331):548553.

52. Tanese K, Hashimoto Y, Berkova Z, Wang Y, Samaniego F, Lee JE, Ekmekcioglu S and Grimm EA. Cell Surface CD74MIF Interactions Drive Melanoma Survival in Response to Interferon- $\gamma$. Journal of Investigative Dermatology. 2015.

53. Mantovani A, Allavena P, Sozzani S, Vecchi A, Locati M and Sica A. (2004). Chemokines in the recruitment and shaping of the leukocyte infiltrate of tumors. Seminars in cancer biology: Elsevier), pp. 155-160.

54. Koga M, Kai H, Egami K, Murohara T, Ikeda A, Yasuoka S, Egashira K, Matsuishi T, Kai M and Kataoka Y. Mutant MCP-1 therapy inhibits tumor angiogenesis and growth of malignant melanoma in mice. Biochemical and biophysical research communications. 2008; 365(2):279-284.

55. Nesbit M, Schaider H, Miller TH and Herlyn M. Lowlevel monocyte chemoattractant protein-1 stimulation of monocytes leads to tumor formation in nontumorigenic melanoma cells. The Journal of Immunology. 2001; 166(11):6483-6490.

56. Gross $\mathrm{O}$, Thomas $\mathrm{CJ}, \dagger \mathrm{GG}$ and $\dagger \mathrm{JT}$. The inflammasome: an integrated view. Immunological Reviews. 2011; 243(1):136-151.

57. DM E, DM W, S V, M P, SM H, NM C, ED F, EM T and HR A. The role of interleukin 1 in growth and metastasis of human cancer xenografts. Clinical Cancer Research An Official Journal of the American Association for Cancer Research. 2006; 12(4):1088-1096.

58. Gehrke S, Otsuka A, Huber R, Meier B, Kistowska M, Fenini G, Cheng P, Dummer R, Kerl K and Contassot E. Metastatic melanoma cell lines do not secrete IL-1 $\beta$ but promote IL-1 $\beta$ production from macrophages. Journal of Dermatological Science. 2014; 74(2):167-169.

59. Björkdahl O, Wingren AG, Hedhund G, Ohlsson L, Dohlsten M. Gene transfer of a hybrid interleukin-1 beta 
gene to B16 mouse melanoma recruits leucocyte subsets and reduces tumour growth in vivo. Cancer immunology, immunotherapy. 1997; 44(5):273-281.

60. Clarke JH, Cha JY, Walsh MD, Gamboni-Robertson F, Banerjee A, Reznikov LL, Dinarello CA, Harken AH and McCarter MD. Melanoma inhibits macrophage activation by suppressing toll-like receptor 4 signaling. Journal of the American College of Surgeons. 2005; 201(3):418-425.

61. Lee N, Zakka LR, Mihm MC and Schatton T. Tumourinfiltrating lymphocytes in melanoma prognosis and cancer immunotherapy. Pathology. 2016.

62. Hirano F, Kaneko K, Tamura H, Dong H, Wang S, Ichikawa M, Rietz C, Flies DB, Lau JS and Zhu G. Blockade of B7$\mathrm{H} 1$ and PD-1 by monoclonal antibodies potentiates cancer therapeutic immunity. Cancer research. 2005; 65(3):10891096.

63. Francisco LM, Sage PT and Sharpe AH. The PD-1 pathway in tolerance and autoimmunity. Immunological reviews. 2010; 236(1):219-242.

64. Boyle GM, Pedley J, Martyn AC, Banducci KJ, Strutton GM, Brown DA, Breit SN and Parsons PG. Macrophage inhibitory cytokine-1 is overexpressed in malignant melanoma and is associated with tumorigenicity. Journal of Investigative Dermatology. 2009; 129(2):383-391.

65. De Wit N, Rijntjes J, Diepstra J, Van Kuppevelt T, Weidle $\mathrm{U}$, Ruiter D and van Muijen G. Analysis of differential gene expression in human melanocytic tumour lesions by custom made oligonucleotide arrays. British journal of cancer. 2005; 92(12):2249-2261.

66. Weeraratna AT, Becker D, Carr KM, Duray PH, Rosenblatt KP, Yang S, Chen Y, Bittner M, Strausberg RL and Riggins GJ. Generation and analysis of melanoma SAGE libraries: SAGE advice on the melanoma transcriptome. Oncogene. 2004; 23(12):2264-2274.

67. Riker AI, Enkemann SA, Fodstad O, Liu S, Ren S, Morris C, Xi Y, Howell P, Metge B, Samant RS, Shevde LA, Li W, Eschrich S, Daud A, Ju J and Matta J. The gene expression profiles of primary and metastatic melanoma yields a transition point of tumor progression and metastasis. BMC medical genomics. 2008; 1:13.

68. Talantov D, Mazumder A, Yu JX, Briggs T, Jiang Y, Backus J, Atkins D and Wang Y. Novel genes associated with malignant melanoma but not benign melanocytic lesions. Clinical cancer research. 2005; 11(20):7234-7242.
69. Repp AC, Mayhew ES, Apte S and Niederkorn JY. Human uveal melanoma cells produce macrophage migrationinhibitory factor to prevent lysis by NK cells. The Journal of Immunology. 2000; 165(2):710-715.

70. Yamashita T, Yoneta A and Hida T. Macrophage inhibitory cytokine-1: a new player in melanoma development. Journal of Investigative Dermatology. 2009; 129(2):262-264.

71. Huh SJ, Chung CY, Sharma A and Robertson GP. Macrophage inhibitory cytokine-1 regulates melanoma vascular development. The American journal of pathology. 2010; 176(6):2948-2957.

72. Shi X, Leng L, Wang T, Wang W, Du X, Li J, McDonald C, Chen Z, Murphy JW and Lolis E. CD44 is the signaling component of the macrophage migration inhibitory factorCD74 receptor complex. Immunity. 2006; 25(4):595-606.

73. Starlets D, Gore Y, Binsky I, Haran M, Harpaz N, Shvidel L, Becker-Herman S, Berrebi A and Shachar I. Cellsurface CD74 initiates a signaling cascade leading to cell proliferation and survival. Blood. 2006; 107(12):48074816.

74. Seo N, Hayakawa S, Takigawa $M$ and Tokura Y. Interleukin-10 expressed at early tumour sites induces subsequent generation of CD4(+) T-regulatory cells and systemic collapse of antitumour immunity. Immunology. 2001; 103(4):449-457.

75. Oka H, Emori Y, Hayashi Y and Nomoto K. Breakdown of Th Cell Immune Responses and Steroidogenic CYP11A1 Expression in CD4 + T Cells in a Murine Model Implanted with B16 Melanoma. Cellular Immunology. 2000; 206(1):715.

76. Kobayashi M, Kobayashi H, Pollard RB and Suzuki F. A pathogenic role of $\mathrm{Th} 2$ cells and their cytokine products on the pulmonary metastasis of murine B16 melanoma. Journal of Immunology. 1998; 160(12):5869-5873.

77. Wynn TA, Chawla A and Pollard JW. Macrophage biology in development, homeostasis and disease. Nature. 2013; 496(7446):445-455.

78. Jinushi M and Komohara Y. Tumor-associated macrophages as an emerging target against tumors: Creating a new path from bench to bedside. Biochim Biophys Acta. 2015; 1855(2):123-130. 